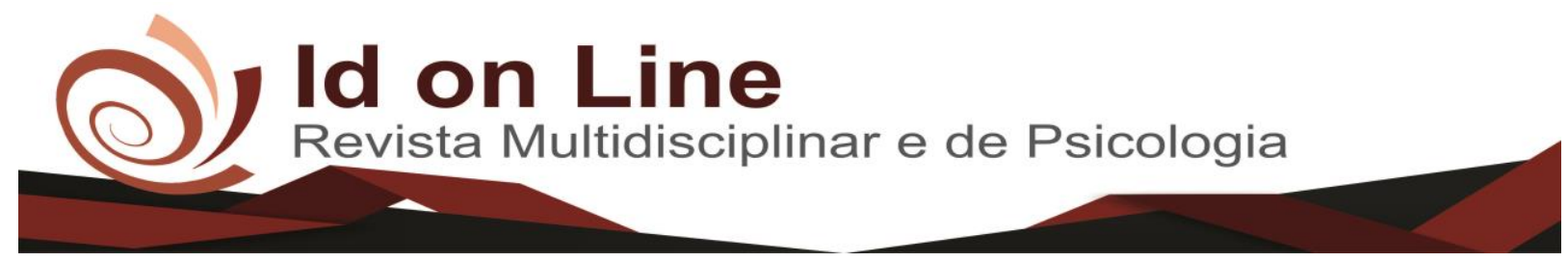

Relato de Caso

\title{
Estruturação do Processo de Formação Interna: Um Estudo de Caso em uma Empresa do Ramo Contábil
}

\author{
Ubaldo de Jesus Fonsecal ${ }^{\text {; Vinicius Motta Oliveira }}{ }^{2}$
}

\begin{abstract}
Resumo: Após a criação de vários instrumentos de fiscalização tributária, pelos governos federais, estaduais e municipais, observou-se existir uma escassez de profissionais aptos a atender essas e outras demandas tanto ao FISCO, quanto a sociedade como um todo. $\mathrm{O}$ objetivo desse artigo é analisar a importância de um processo estruturado de formação profissional interna para a qualificação e capacitação dos colaboradores contábeis. Desenvolveu-se, neste estudo uma pesquisa exploratória e descritiva, com tratamento dos dados pelo método qualitativo. Através do estudo, verificou-se que na empresa não existe um processo estruturado de formação profissional interna e a mesma opta em contratar colaboradores sem experiência devido a seus baixo custo. Assim, sugere-se a estruturação de um processo interno de formação para impactar diretamente no desempenho da equipe, tornando-os preparados para desenvolver suas funções com agilidade, atendendo com eficiência e eficácia, as demandas ora impostas pelos governos e pela sociedade.
\end{abstract}

Palavras-Chave: Qualificação e Capacitação; Processo estruturado; Desempenho; Eficiência e Eficácia.

\section{The Internal Structure of Training Process: A Case Study in a Company of Accounting Branch}

\begin{abstract}
After the creation of several instruments of tax inspection, by the federal, state and municipal governments, there was a shortage of professionals able to meet these and other demands both FISCO and society as a whole. The purpose of this article is to analyze the importance of a structured process of internal professional training for the qualification and qualification of the accounting collaborators. In this study, an exploratory and descriptive study was developed, with data treatment by the qualitative method. Through the study, it was verified that in the company there is no structured process of internal professional training and the same chooses to hire inexperienced employees due to their low cost. Thus, we suggest structuring an internal training process to directly impact the performance of the team, making them ready to perform their functions with agility, meeting efficiently and effectively the demands imposed by governments and society.
\end{abstract}

Keywords: Qualification and Training; Structured process; Performance; Efficiency and efficacy.

\footnotetext{
${ }^{1}$ Administrador e Bacharel em Ciências Contábeis. Especialista em Docência no Ensino Superior pelo Centro Universitário Barão de Mauá - CUBM, Ribeirão Preto, São Paulo, Brasil. Especialista em Gestão Estratégica e Negócios pela Universidade do Estado da Bahia - UNEB, ubaldog12@yahoo.com.br, Santo Antônio de Jesus, Bahia, Brasil.

2 Bacharel em Ciências Contábeis. Mestre em Desenvolvimento Regional e meio Ambiente pela Faculdade Maria Milza - FAMAM. Coordenador do curso de Graduação de Ciências Contábeis da Faculdade de Ciências e Empreendedorismo - FACEMP, vinicius.motta@facemp.edu.br, Santo Antônio de Jesus, Bahia, Brasil.
} 


\section{Introdução}

O século XXI, está sendo marcado por inúmeras crises no cenário empresarial, (fechamento de empresas), e por conseguinte profissional, (perca de postos de trabalho), de forma global. Conforme dados do $\mathrm{IBGE}^{3}$ (2014), cerca de 944 mil empresas pediram baixa nas juntas comerciais no nosso país, o (Brasil). Assim, o mesmo órgão governamental, apurou também que o mercado empresarial perdeu 1,6 (um milhão e seiscentos mil), assalariados em relação a 2014, segundo o IBGE, essa foi a primeira vez que houve redução no pessoal assalariado desde 2008, quando o estudo foi iniciado. Segundo a OIT ${ }^{4}$, o Brasil em (2017), será o país onde o desemprego vai ter o maior aumento entre as 20 economias mais desenvolvidas do mundo, a previsão é de 1,2 (um milhão e duzentos mil), assalariados a menos no mercado de trabalho, ou seja, de três desempregados no mundo, um será brasileiro, só perdendo para China e Índia.

Tentando reverter tal fato, o governo brasileiro através da Câmara Federal, criou e aprovou o projeto de Lei $\mathrm{n}^{\circ} 38$, de 2017, que em 13 de Julho de 2017, foi sancionado pelo Presidente da República, criando assim, a lei no 13.467, denominada de "reforma trabalhista", criando uma flexibilização na $\mathrm{CLT}^{5}$, e facilitando direta e sistemática a relação entre empresários e empregados, evitando demissões, e legalizando outras formas de trabalho antes não assistidas pela lei.

Contudo, observar-se que boa parte da classe laboral desempregada é formada em sua maioria por pessoas não qualificadas nem capacitadas profissionalmente, porém a escassez não é generalizada e sim em setores específicos da economia. Segundo o IBGE, a falta de mão de obra qualificada é a causa de gargalos/obstáculos à inovação.

Esse apagão de mão de obra qualificada e capacitada, também atingiu o mercado contábil, pois, após a criação de vários instrumentos de fiscalização tributária, como: a NF-e pelo Ajuste SINIEF no 7, em 30/09/2005, o SPED $^{6}$ pelo Decreto $n^{\circ} 6.022$ em 22/01/2007, e a NFC-e pelo Decreto $n^{\circ} 17.878$ em 23/08/2017. Observou-se haver uma escassez de profissionais aptos a atender essas e outras demandas ao FISCO e a sociedade como um todo.

\footnotetext{
${ }^{3}$ IBGE - Instituto Brasileiro de Geografia e Estatística.

${ }^{4}$ OIT - Organização Internacional do Trabalho, agência integrante da ONU (Organização das Nações Unidas).

5 CLT - Consolidação das Leis do Trabalho. É uma norma legislativa de regulamentação das leis referentes ao Direito do Trabalho e do Direito Processual do Trabalho no Brasil.

${ }^{6}$ SPED - Sistema Público de Escrituração Digital. Trata-se de uma solução tecnológica que oficializa os arquivos digitais das escriturações fiscal e contábil dos sistemas empresariais dentro de um formato específico e padronizado.
}

103 Id on Line Rev. Mult. Psic. V.12, N. N. 41, p.102-123, 2018 - ISSN 1981-1179 
A evidenciação desses fatos, pressupõe a necessidade de um processo de formação profissional interno e estruturado, aplicado dentro das empresas a seus colaboradores, ou seja, uma melhor qualificação e capacitação dessa mão de obra, para que esses colaboradores internos, possam maximizar seus resultados e propiciar maiores ganhos para si, e para a empresa, tanto no âmbito profissional, quando no âmbito financeiro.

Buscando responder ao problema de pesquisa, o estudo tem como objetivo geral analisar a importância de um processo estruturado de formação profissional interna para a qualificação e capacitação dos colaboradores contábeis como ferramenta de maximização de resultados em uma contabilidade do recôncavo da Bahia.

\section{Formação Profissional}

A formação profissional começou com a estereotipização do trabalhador em nosso país, pois a classe dominante da época acreditava que quem fazia trabalhos pesados e de profissões manuais não precisavam ser formados ou profissionalizados (índios, e negros, por estarem na condição de servidão e ou escravidão). Fonseca (1961, p.68), afirma que “... habituou-se o povo de nossa terra a ver aquela forma de ensino como destinada somente a elementos das mais baixas categorias sociais".

Tal situação só começou a mudar segundo Garcia (1996, p.1):

Com a descoberta do ouro em Minas Gerais apareceram as Casas de Fundição e de Moeda, e com elas a necessidade do ensino de ofícios para aprendizes trabalharem nestas Casas. A aprendizagem feita nas Casas da Moeda diferenciava-se da realizada nos engenhos, pois só era destinada aos homens brancos, filhos dos empregados da própria Casa. Outra diferença era que aqueles que aprendiam o ofício, nos engenhos, faziam-no de forma assistemática e não precisavam provar o seu conhecimento prático por meio de exames. Nas Casas de Moeda os aprendizes, no fim do período de cinco a seis anos, tinham que demonstrar as suas habilidades perante uma banca examinadora e, sendo aprovados recebiam uma certidão de aprovação.

Enquanto a aprendizagem feita nas casas da moeda eram destinadas a homens brancos que depois de 5 ou 6 meses passavam por uma banca de examinação para sua aprovação ou não para exercer tal oficio. Os aprendizes dos engenhos eram escravos e não precisavam passar por exames para provar seu conhecimento prático. Ou seja, após a descoberta do ouro, percebe-se 
uma diferença tangente no trato referente a formação profissional, pois pelo menos os homens brancos já precisavam formar-se para exercer um oficio.

Garcia (1996, p.5), afirma que com o fim da escravidão e a proclamação da República, nascia a perspectiva de alterar o panorama em relação ao ensino de ofícios. Surgia assim a necessidade de formar e profissionalizar a população para que a mesma viesse a tornar-se mais produtiva e eficiente.

É importante ressaltar que boa parte da força laboral disponível em nosso país nos dias atuais, (século XXI), não teve acesso à educação em nível de formação profissional e dessa forma os mesmos executam tarefas simples que não necessitam de conhecimento cientifico/tecnológico.

\section{Modalidades de Formação Profissional}

O termo formação tem origem latina (formatio), e conceitua-se como ação ou efeito de formar ou se formar algo. Para o $\mathrm{SNQ}^{7}$ (2017), "formação profissional” é a dotação do indivíduo de ou por competências com vista ao exercício de profissões. Já nos dias presentes a formação é associada a ampliação de qualidades dos indivíduos, onde os mesmos reciclam seus conhecimentos para continuarem inseridos no processo de transformação da sociedade e de si mesmo.

Para Libanio (2010, págs.13-14):

\footnotetext{
Formar-se é tomar em suas mãos seu próprio desenvolvimento e destino num duplo movimento de ampliação de suas qualidades humanas, profissionais, religiosas e de compromisso com a transformação da sociedade em que se vive [...] é participar do processo construtivo da sociedade [...] na obra conjunta, coletiva, de construir um convívio humano e saudável.
}

A escolha da profissão é um processo ao longo do qual o sujeito irá decidir pela alternativa que mais lhe agrada. Assim, vários tipos ou modalidades de formações profissionais surgem, buscando atender e ampliar as qualidades humanas.

\footnotetext{
${ }^{7}$ SNQ - Sistema Nacional de Qualificações. 
Conforme artigo 21 da Lei de Diretrizes e Bases da Educação (LDB), a educação brasileira é dividida em dois níveis de ensino: educação básica e o ensino superior, e o ensino superior é formado por:

* Bacharelado que é uma formação teórica e prática;

* Licenciatura forma professores;

* Tecnológico modalidade de curso criada para suprir as necessidades mais imediatas do mercado de trabalho;

* E a educação à distância chamados de cursos não presenciais. Os cursos são geralmente ministrados via correspondência, rádio, TV ou internet.

Os tipos ou modalidades de formação profissional se entrelaçam em uma verdadeira teia de puro conhecimento, propiciando desenvolvimento através de um processo de que visa atender as necessidades do mercado de trabalho, e também as necessidades intrínsecas do formando.

\section{Processo de formação}

O processo de formação é algo complexo, pois não depende apenas dos conhecimentos prévios do indivíduo envolvido no processo.

O Portal da Educação (2012), explica que o processo de formação educacional, assemelha-se ao processo de formação industrial, onde existem as entradas dos insumos, a produção ou transformação dos mesmos, e por fim um produto acabado.

O processo de formação profissional se compara a produção de um bem físico, pois o aluno entra no processo com o seu conhecimento vivencial, depois o mesmo passa por estágios de construção, transformação e aquisição de novos conhecimentos, até a criação de um produto final acabado que é o conhecimento da sua área de atuação profissional, que estará pronto para ser utilizado ou colocado à disposição do mercado. 


\section{Modelo Estruturado de Formação}

Uma empresa precisa ter trabalhadores aptos para o bom desenvolvimento de suas funções laborais, com muita eficiência, usando os gargalos do mercado a seu favor, e aumentado a lucratividade. Contudo para que tal situação aconteça é imprescindível a criação e utilização de um modelo estruturado de formação para garantir que essa mão de obra seja, qualificada e capacitada para tal. Para Chiavenato (2014, p.495), "O processo educacional de curto prazo e aplicado de maneira sistemática e organizada, pelo qual as pessoas aprendem conhecimentos, atitudes e competências em função de objetivos previamente definidos", pode atender esse modelo de formação estruturado.

Lacombe (2011, p.380), afirma que:

"Qualquer atividade que contribua para tornar uma pessoa apta a exercer sua função ou atividade, para aumentar a sua capacidade para exercer melhor essas funções ou atividades, ou para prepará-la para exercer de forma eficiente novas funções ou atividades".

Todo treinamento dado dentro ou fora das empresas deve ser visto pelos colaboradores como uma forma sólida e continuada de absorção e ampliação de conhecimento.

Vidigal (2012), estrutura um modelo de formação, visando ao atendimento das necessidades do mercado por profissionais qualificados e capacitados aptos ao exercício profissional, e esse modelo perpassa por estágios como a:

\footnotetext{
Educação formal: forma de ensino aplicado em escolas, sejam elas de $1^{\circ}, 2^{\circ}$ ou $3^{\circ}$ graus. Educação informal: diverge da formal, pois é obtida por observações, fora das escolas convencionais, sejam elas municipais, estaduais, federais ou particulares. Cursos profissionalizantes e técnicos: qualificação latente em nosso país (Brasil), pois prepara o aluno de forma tecnicista e com rapidez para atender as necessidades mercadológicas. Treinamento empresarial: geralmente é interno, gerando qualificação especifica aos funcionários, sem custo aos mesmos.
}

Os modelos estruturados de formação servem para tornar os profissionais mais competitivos, dentro de um cenário globalizado, os tornando destaque em nível profissional e informacional. Pois, "nessa onda de reestruturação, as pessoas deixam de ser recurso produtivo ou mero agente passivo da administração para se tornar agentes ativos e proativos do negócio." (CHIAVENATO, 2014, p.338). 


\section{Qualificação e capacitação profissional}

Devido a acirrada concorrência no cenário empresarial e as constantes mudanças nas legislações e no atendimento a obrigações acessórias de cunho tributário nas áreas contábeis e fiscais impostas pelos governos (Municipais, Estaduais e Federais), a uma necessidade de mercado por profissionais altamente qualificados e capacitados para atender tais demandas. É preciso que tais colaboradores sejam eles contadores ou não, entendam que o conhecimento adquiro até então, não é um fim em si, e sim um início, e sendo assim, à necessidade de um constante aprimoramento intelectual. "A partir dessa observação constatamos que a responsabilidade pelo desenvolvimento e capacitação divide-se em duas partes proporcionais; empresa e funcionário". (GRAMIGNA, 2012, p.122).

Contudo a de se definir exatamente o que é, e para que serve tanto a capacitação quando a qualificação profissional, para que os colaboradores saibam o que fazer primeiro para estarem atualizados e treinados. Chiavenato (2014, p.267), argumenta que "o treinamento é uma maneira eficaz de agregar valor às pessoas, à organização e aos clientes. Ele enriquece o patrimônio humano das organizações". Tanto a qualificação quanto a capacitação são treinamentos, entretanto, vale salientar que cada um é especifico em si.

A qualificação perpassa pela preparação de maneira teórica, técnica e operacional, geralmente dentro de instituições de ensino e demanda investimento financeiro, e em parte atende as necessidades do mercado, contudo esse conhecimento é adquirido com efeito generalista, ou seja, sem especificidades, onde os estudantes saem com condições, porém não indica que estejam prontos a exercer funções no mercado de trabalho. Vidigal (2012) aborda que "a decisão de investimento em qualificação é vantajosa quando o valor dos benefícios gerados pela qualificação é superior ao valor dos custos".

A capacitação por sua vez prepara o colaborador para entender o "por que" de fazer-se alguma coisa, é algo especifico e coeso onde aprende-se a enfrentar, criar, resolver e melhorar o que já se faz o tornando-o apto e o dando autonomia e autoconfiança.

De forma direta e sem devaneios, o futuro é favorável e promissor para os profissionais que se permitem reciclar seus conhecimentos, porque a velocidade informacional dos dias atuais não permite que o profissional seja desleixado frente às mudanças. Pois, a todo dia a clientela muda suas necessidades, e cria novas expectativas forçando as empresas a prover melhor qualidade, melhores serviços e garantindo também a responsabilidade social (CHIAVENATO, 2014). 
Por tanto nota-se uma dualidade entre qualificação (base, formação) e capacitação (especificidade, competência), pois ambas juntas conjugam-se, todo profissional precisa primeiro qualificar-se, adquirindo conhecimentos e experiências e por conseguinte, capacitarse, desenvolvendo novas habilidades e aprimorando outras.

\title{
Maximização de resultados para empresa do ramo contábil
}

O mercado precisa de profissionais que estejam prontos a enfrentar desafios no laboro, que saibam unir teoria e prática, e que contribuam para o crescimento pessoal e da empresa.

Segundo Iudicibus (2011, p.19):

\begin{abstract}
A contabilidade é o grande instrumento que auxilia a administração a tomar decisões. $\mathrm{Na}$ verdade, ela coleta todos os dados econômicos, mensurando os monetariamente, registrando-os e sumarizando-os em forma de relatórios ou de comunicados, que contribuem sobremaneira para a tomada de decisões.
\end{abstract}

O profissional bem formado (qualificado e capacitado), torna-se uma peça indispensável na engrenagem da empresa, sendo ele o maximizador eficiente do processo estratégico, através da geração e interpretação dos indicadores de crescimento e rentabilidade, que propicia a tomada direta de decisões.

\section{Formação Profissional Contábil}

Ressalta-se que nem todos os contabilistas (pessoas que trabalham em um escritório contábil), são técnicos ou bacharéis em contabilidade, e quando falamos de formação profissional no que tange a formação profissional contábil, abrangemos neste artigo todos os contabilistas que atuam ou desempenham funções dentro de setores de uma contabilidade, sendo eles responsáveis ou não pela parte técnica dos mesmos.

Essa mão de obra não qualificada teoricamente (por não ser técnico ou bacharel) em contabilidade, é possuidora de um conhecimento prático, latente e cotidiano, e precisa está em constante processo de formação profissional para atender as demandas impostas pelos governos e pela sociedade em geral. O exercício de uma profissão demanda a aquisição de pleno 
conhecimento, o domínio sobre a tarefa e sobre a forma de executá-la, além de atualização constante e aperfeiçoamento cultural (SÁ, 2009, p.165).

Segundo SÁ (2009, p.146):

Entre os diversos campos profissionais, o Contabilista tem a seu dispor um dos maiores mercados, pois nenhuma empresa e nenhuma instituição podem dispensar sua assistência constante; por isso, proporcionalmente, se agigantam as responsabilidades e os deveres, mas também as dignidades e as recompensas pelo exercício.

Os contabilistas sem formação (técnica ou bacharelado) são a maior parte da força produtiva laboral dos escritórios contábeis, sendo os mesmos responsáveis pela elaboração de diversas obrigações acessórias e relatórios que são enviados aos governos (municipais, estaduais e federais), além de visitas a clientes para sanar dúvidas contábeis.

Segundo SÁ (2009, p.153):

A especialização é a solução para a qualidade do trabalho e para a sociedade, como maior veículo de utilidade; sociólogos, como Durkheim, inclusive, proclamaram ser a vida das classes aquela que se assemelha a de uma família, fazendo a apologia das especializações.

Diante desta contextualização é importantíssimo saber se os mesmos vem sendo qualificados e capacitados para maximizar os resultados das empresas em que estão inseridos como contabilistas. Pois o processo de formação profissional é o agregar de atividades que propiciam conhecimentos, habilidades e atitudes adquiridos através da teoria/prática e que são exigidos para o exercício pleno de uma função ligados a uma profissão.

\section{Estágio: curricular e extracurricular}

O estágio faz o somatório do conhecimento teórico, com o conhecimento prático, alinhando o processo de formação dos educandos na busca por seu desenvolvimento profissional e na própria escolha de sua profissão futura.

De acordo com Santos (2014, págs.20-21):

Oficialmente existem duas modalidades de estágio, o obrigatório e não obrigatório. Nenhum dos dois vincula o colaborador estagiário a empresa como funcionário efetivo. O estágio curricular (obrigatório), está inserido no curriculum das instituições de ensino em seus cursos e tem horários e requisitos para o aluno ser 
considerado aprovado no mesmo, através do acompanhamento de docentes autorizados para tal na instituição de ensino, assim como pelo supervisor da organização concedente geralmente representado pelo Gestor de Recursos Humanos ou por um profissional com formação superior e experiência na área do curso do estagiário.

Já o estágio não curricular ou extracurricular (não obrigatório), constitui-se como atividade complementar à formação profissional, social e cultural do estagiário, sendo realizado por sua livre escolha. Esta modalidade de estágio é desenvolvida como atividade opcional acrescida à carga horária regular e obrigatória do curso. Todo estudante, independente do curso que queria complementar sua formação profissional, pode realizar estágios não obrigatórios. A única exigência é que o plano de atividades esteja previsto no projeto pedagógico do curso e também que o estágio seja acompanhado pela instituição de ensino.

O estágio é uma parte importantíssima dentro do processo de formação profissional. De acordo com o art. $1^{\circ}$ da Lei ${ }^{\circ} 11.788 / 2008$ :

Estágio é o ato educativo escolar supervisionado, desenvolvido no ambiente de trabalho, que visa à preparação para o trabalho produtivo de educandos que estejam frequentando o ensino regular em instituições de educação superior, de educação profissional, de ensino médio, da educação especial e dos anos finais do ensino fundamental, na modalidade profissional da educação de jovens e adultos.

Por muitas vezes o estágio é a primeira porta aberta para o conhecimento do ramo contábil, pois diversos estudantes do ensino médio ou superior pleiteiam tais vagas com o intuito de desenvolverem uma melhor preparação para quando estiverem inseridos de fato no ambiente profissional produtivo.

\section{Método Adotado}

Afim de direcionar aos objetivos propostos está pesquisa é classificada como um "processo formal e sistemático de desenvolvimento do método científico. O objetivo fundamental da pesquisa é descobrir respostas para problemas mediante o emprego de procedimentos científicos" (GIL 2008, p.42).

Quanto aos objetivos desse estudo a pesquisa delineou-se como de natureza exploratória e descritiva, pois a pesquisa exploratória pode ser classificada de duas formas: bibliográfica e ou um estudo de caso (Gil 2017), portanto, neste estudo o levantamento metodológico foi de cunho bibliográfico em Leis, Artigos, Decretos, Projetos, Livros e Sites institucionais. 
Para Beuren (2008, p.81) “a pesquisa descritiva configura-se como um estudo intermediário entre a pesquisa exploratória e a explicativa, ou seja, não é tão preliminar como a primeira nem tão aprofundada como a segunda". A descrição dos fatos consiste em identificálos ou compará-los, sem que se mudem suas características.

Quanto aos procedimentos, a pesquisa se delineia como um estudo de caso, o qual será realizado em uma contabilidade do recôncavo da Bahia. Beuren (2008, p.84), afirma que "a pesquisa do tipo estudo de caso caracteriza-se principalmente pelo estudo concentrado de um único caso”. Este estudo por ser especifico é preferido para aprofundamento.

Quanto à natureza, a pesquisa classifica-se como aplicada. Gil (2017), define pesquisa aplicada como aquela que "objetiva-se gerar conhecimentos que serão aplicados de forma prática e dirigidos a solução de problemas específicos".

Quanto à abordagem, a pesquisa classifica-se como qualitativa, o método qualitativo, justifica-se devido ao problema em questão que advêm de observações na empresa e interpretações dos dados obtidos. Para Beuren (2008, p.92): "na pesquisa qualitativa concebemse análises mais profundas em relação ao fenômeno que está sendo estudado".

A população total da empresa é de 28 (vinte e oito) colaboradores, porém o questionário de pesquisa foi aplicado dentro de 3 (três) setores da empresa, à 7 (sete) colaboradores: 3 (três) do setor fiscal, 3 (três) do setor contábil e 1 (um) do setor pessoal, pois os mesmos são os responsáveis por tais setores pesquisados dentro da contabilidade.

Foi utilizado como técnica de coleta de dados o questionário (aberto e fechado), que constou de 13 perguntas, aplicadas pelo pesquisador em 21 de fevereiro de 2018 . O questionário antes de ser aplicado aos colaboradores da empresa, foi aplicado a 2 (dois) professores de graduação e pós graduação: um dos professores é mestre em administração de empresas e o outro professor (a) é mestra em educação. Tal método de teste é conhecido como Delphi, que para Thomas e Nelson (2002), "se caracteriza como uma forma de encontrar consenso entre especialistas sobre pontos relevantes". O questionário é um conjunto de questões com o objetivo de obter informações escritas dos sujeitos pesquisados. Com questões pertinentes ao objeto de estudo sendo formulado claramente e de fácil compreensão (SEVERINO, 2016). Os resultados da pesquisa serão apresentados por meio de tabelas, com o auxílio do programa Microsoft Excel 2013. 


\section{Percurso Metodológico}

Para MINAYO (1994, p.22), “É a metodologia que explicita as opções teóricas fundamentais, expõe as implicações do caminho escolhido para compreender determinada realidade e o homem em relação com ela". Considerando-se as fases metodológicas de uma pesquisa, podemos dizer que a nossa foi sistematizada em quatro etapas, a saber: (1) definição do objeto; (2) foram feitas observações; (3) descrição e interpretação; (4) conclusão. As principais operações metodológicas foram: (1) revisão de literatura; (2) definição do modelo de pesquisa como exploratória e descritiva; (3) definição do problema; (4) definição do corpo da pesquisa; (5) definição da dimensão e do dispositivo de análise; (6) pré- teste e revisão da dimensão e do dispositivo de análise; (7) análise descritiva e interpretativa; (8) definição do método de abordagem como qualitativo e elaboração das generalizações.

\section{Análise e Discussão dos Resultados}

Este estudo foi desenvolvido em uma empresa do ramo contábil denominada de contabilidade X2 (nome fictício), tal empresa e sediada em uma cidade do território de identidade denominado de recôncavo, no interior do estado da Bahia, a contabilidade atua no mercado a mais de 30 anos, e seu quadro funcional é formado por 28 (vinte e oito) colaboradores, porém o questionário de pesquisa foi aplicado dentro de 3 (três) setores da empresa, à 7 (sete) colaboradores: 3 (três) do setor fiscal, 3 (três) do setor contábil e 1 (um) do setor pessoal, pois os mesmos são os responsáveis por tais setores pesquisados dentro da contabilidade. 


\section{Análise feita com os Colaboradores}

Tabela 01 - Nível de formação - FEV/2018

\begin{tabular}{cc}
\hline & Nível de formação \\
\hline 1. Básica & 1 Básica \\
\hline Nível fundamental & $\mathbf{3}$ \\
\hline Nível médio & 2 Técnico \\
\hline 2. Técnico & \\
\hline Ensino técnico & 3. Superior \\
\hline 3. Superior & $\mathbf{1}$ \\
\hline Completo & \\
\hline Incompleto & \\
\hline Especialização & $\mathbf{7}$ \\
\hline Mestrado & \\
\hline Doutorado & \\
\hline Pós - doutorado & \\
\hline Total &
\end{tabular}

Fonte: Pesquisa 2018.

Observou-se na tabela 01, que dos 7 (sete) colaboradores pesquisados 3 (três) possuem o nível médio completo, 1 (um) possui o ensino superior completo e 3 (três) deles possui o ensino superior incompleto. Segundo SÁ (2009, p.55), “a utilidade e a qualidade do trabalho tendem a ser tanto maiores quanto maior for à cultura do profissional”. Quanto melhor formado for o profissional, maior será seu arcabouço de conhecimentos e vivencias.

Tabela 02 - Tempo de trabalho na empresa - FEV/2018

\begin{tabular}{cc}
\hline \multicolumn{1}{c}{ Tempo de trabalho na empresa } \\
\hline Até 1 ano & $\mathbf{N}^{\mathbf{0}}$ \\
\hline $\mathbf{1}$ a 5 anos & 2 \\
\hline $\mathbf{5}$ a 10 anos & 3 \\
\hline Acima de 10 anos & 1 \\
\hline Total & 1 \\
\hline
\end{tabular}

Fonte: Pesquisa 2018. 
Constatou-se na tabela 02 , que 2 (dois) dos colaboradores possui até um ano de empresa, 3 (três) deles de 1 a 5 anos, 1 (um) entre 5 a 10 anos e 1 (um) acima de 10 anos de serviço prestado a empresa.

Tabela 03 - Setor de trabalho dentro da empresa - FEV/2018

\section{Setor de trabalho dentro da empresa}

\begin{tabular}{|cc}
\hline Colaborador 1 & Contábil \\
\hline Colaborador 2 & Fiscal \\
\hline Colaborador 3 & Fiscal \\
\hline Colaborador 4 & Fiscal \\
\hline Colaborador 5 & Pessoal \\
\hline Colaborador 6 & Contábil \\
\hline Colaborador 7 & Contábil \\
\hline
\end{tabular}

Fonte: Pesquisa 2018.

Em relação ao setor de trabalho dentro da empresa, a tabela 03, demonstrou que 1 (um) colaborador trabalha no setor pessoal, 3 (três) deles trabalham no setor contábil e 3 (três) trabalham no setor fiscal da empresa.

Tabela 04 - Experiência para executar a função - FEV/2018

Quando contratado (a), pela empresa, você já possuía experiência para $\quad$ SIM NÃO executar a função?

Total $\quad 1 \quad 6$

Fonte: Pesquisa 2018.

Na tabela 04, apenas 1 (um) colaborador afirmou ter experiência para executar a função para qual foi contratado, pois já havia trabalhado em outra empresa, onde aprendeu, os outros 6 (seis) colaboradores afirmaram não ter experiência alguma quando foram contratados. 
Tabela 05 - Concessão de treinamento - FEV/2018

A empresa lhe concedeu algum tipo de treinamento interno para lhe tornar apto a trabalhar em sua função/setor?

\begin{tabular}{ccccc}
\hline Colaboradores & Função/setor & SIM & NãO & $\begin{array}{c}\text { Qtd. de } \\
\text { treinamentos }\end{array}$ \\
\hline 1 & Contábil & $\mathbf{X}$ & & $\mathbf{2}$ \\
\hline 2 & Fiscal & & $\mathbf{X}$ & \\
\hline 3 & Fiscal & $\mathbf{X}$ & \\
\hline 4 & Fiscal & $\mathbf{X}$ & \\
\hline 5 & Pessoal & $\mathbf{X}$ & \\
\hline 6 & Contábil & & $\mathbf{X}$ & \\
\hline 7 & Contábil & & $\mathbf{X}$ & \\
\hline Total & & $\mathbf{1}$ & $\mathbf{6}$ & $\mathbf{2}$ \\
\hline
\end{tabular}

Fonte: Pesquisa 2018.

Na tabela 05, apenas 1 (um) dos colaboradores do setor contábil afirmou já ter recebido treinamento por parte da empresa para trabalhar em sua função, e a quantidade de treinamentos dados foram dois. Já os outros 6 (seis) colaboradores nunca tiveram concessão de nenhum treinamento em seu favor. "Para seu benefício profissional e como cidadão, o Contador deve manter-se atualizado não apenas com as novidades de sua profissão, mas de forma mais ampla [...]" (IUDICIBUS, 2011, p.7). A busca por conhecimento deve ser incessante, pois o acumulo do mesmo, propicia à abertura de um leque de variedades intelectuais que facilita a solução de problemas.

Tabela 06 - Meios de atualização para exercício da função na empresa - FEV/2018 Quais meios são utilizados pela empresa para manter seus colaboradores atualizados para o exercício de sua função em seu setor?

\section{Meios utilizados}

Revistas eletrônicas $\mathbf{3}$

Cursos online

Seminários

Congressos, convenções

Viagens

Rede de contatos

Cursos internos

\begin{tabular}{cc}
\hline Outros & $\mathbf{3}$ \\
\hline Total & $\mathbf{7}$
\end{tabular}

Fonte: Pesquisa 2018. 
Quanto aos meios para atualização para exercício da função na empresa, a tabela 06, revelou que 3 (três) dos colaboradores se atualizam por revistas eletrônicas ligadas a seus setores, 1 (um) deles se atualiza por meio de sua rede de contatos pessoal, e 3 (três) deles afirmam que se atualizam com colegas mais experientes do seu setor.

Tabela 07 - Existência de mecanismo para medir a qualidade e o desempenho - FEV/2018 A empresa possui algum tipo de mecanismo para medir a qualidade e $\quad$ SIM $\quad$ NÃO o desempenho em relação ao trabalho desenvolvido em seu setor?

Total

16

Fonte: Pesquisa 2018.

Na tabela 07, 1 (um) dos colaboradores afirmou que o gerente da empresa aplicava provas para medir a qualidade e o desempenho no setor, contudo, 6 (seis) colaboradores afirmam não existir tal mecanismo em seus setores dentro da empresa.

Tabela 08 - Existência de algum tipo de incentivo financeiro como investimento - FEV/2018 A empresa já lhe deu algum tipo de incentivo financeiro como SIM NÃO investimento para seu processo de formação profissional?

Total

16

Fonte: Pesquisa 2018.

$\mathrm{Na}$ tabela 08, apenas 1 (um) dos colaboradores afirma ter recebido algum tipo de incentivo financeiro como investimento para seu processo de formação, que foi o pagamento de dois cursos pela empresa, porém os outros 6 (seis) colaborares afirmam nunca terem recebido nada.

Tabela 09 - O que é formação - FEV/2018

Você sabe o que é formação profissional?

Total

SIM NÃO

Fonte: Pesquisa 2018.

Na tabela 09, 5 (cinco) colaboradores afirmaram saber o que é formação profissional e 2 (dois) deles afirmaram não saber. Se a resposta à pergunta fosse sim, os mesmos teriam que justificar suas respostas. Sendo assim 3 (três) justificaram como sendo um conjunto de atividades que tem como objetivo a aquisição de conhecimentos e capacidades para a execução 
de sua profissão, já 2 (dois) justificaram como sendo o desenvolvimento de habilidades técnicas e teóricas sobre determinado assunto.

Tabela 10 - O que é qualificação - FEV/2018

\begin{tabular}{lccc}
\hline Você sabe o que é qualificação profissional? & SIM & NÃO \\
\hline Total & 6 & 1 \\
\hline
\end{tabular}

Fonte: Pesquisa 2018.

Na tabela 10, 6 (seis) colaboradores afirmaram saber o que é qualificação profissional e 1 (um) deles afirmou não saber. Se a resposta à pergunta fosse sim, os mesmos teriam que justificar suas respostas. Sendo assim 3 (três) justificaram como sendo a preparação do funcionário através de investimento por parte do patrão, 1 (um) justificou como sendo o aprimoramento do conhecimento já existente, e por fim, 2 (dois) justificaram como sendo uma preparação para aprimorar suas habilidades em uma determinada área.

Tabela 11 - O que é capacitação - FEV/2018

Você sabe o que é capacitação profissional?

Total

SIM NÃO

Fonte: Pesquisa 2018.

Referente a indagação feita na tabela 11, 5 (cinco) colaboradores afirmaram saber o que é capacitação profissional e 2 (dois) deles afirmaram não saber. Se a resposta à pergunta fosse sim, os mesmos teriam que justificar suas respostas. Assim 1 (um) justificou como sendo a possibilidade de acesso a oportunidades, 2 (dois) justificaram como sendo um investimento para tornar-se um profissional de qualidade, e 2 (dois) justificaram como sendo um treinamento especifico para o desempenho de atividades práticas e teóricas.

Tabela 12 - Existência de um processo estruturado de formação profissional interna FEV/2018

\begin{tabular}{|c|c|c|}
\hline $\begin{array}{l}\text { Existe dentro da empresa um processo estruturado de formação } \\
\text { profissional interna para a qualificação e capacitação dos } \\
\text { colaboradores contábeis? }\end{array}$ & SIM & NÃO \\
\hline Total & 0 & 7 \\
\hline
\end{tabular}

Fonte: Pesquisa 2018. 
Todos os colaboradores responderam na tabela 12, não existir dentro da empresa qualquer tipo de processo estruturado de formação interna para qualificá-los e capacitá-los. Para Silva (2010, p.26) “O mercado atual requer modernidade, criatividade, novas tecnologias, novos conhecimentos e mudanças urgentes na visão através dos paradigmas, impondo com isso, um desafio: o de continuar competindo". E para continuar competindo se faz necessário a existência de um processo de formação que abra a visão tanto do colaborador quanto do empregador.

Tabela 13 - Criação de um processo estruturado de formação profissional interna - FEV/2018 Você acha importante a criação de um processo estruturado de SIM NÃO formação profissional interna na empresa que você trabalha?

Total $7 \quad 0$

Fonte: Pesquisa 2018.

Todos os contabilistas responderam na tabela 13, que acham de extrema importância a criação de um processo estruturado de formação profissional interna na empresa.

E se a resposta à pergunta fosse sim, os mesmos teriam que justificar o porquê da criação. 1 (um) respondeu que a criação desse processo acabaria com seu abismo profissional, outro respondeu que dessa forma iria adquirir mais conhecimento, 2 (dois) afirmaram que iriam crescer mais rápido dentro da empresa, e 3 (três) deles justificaram que isso iria impactar diretamente no desempenho da equipe tornando-os preparados para desenvolver suas funções com agilidade, eficiência e eficácia. "A estrutura conceitual básica da Contabilidade emerge desse processo com a finalidade de propiciar [...] mecanismos que os orientem no sentido de organizar o processo de geração de informações para atender as necessidades dos usuários" (FÁVERO, 2011, p.29).

Então, quanto mais estruturado for o processo de formação profissional interna, essa estrutura propiciará uma produção de melhor qualidade, evitando erros, além de potencializar maiores lucros através da satisfação do cliente com o serviço recebido. 


\section{Considerações Finais}

O objetivo geral da pesquisa foi analisar a importância de um processo estruturado de formação profissional interna para a qualificação e capacitação dos colaboradores contábeis como ferramenta de maximização de resultados em uma contabilidade do recôncavo da Bahia. Contudo para que tal objetivo final torne-se atingível, fez-se necessário examinar como acontece o processo de formação, qualificação e capacitação profissional na empresa, Porém, após a aplicação da pesquisa constatou-se por unanimidade, ou seja, todos os colaboradores pesquisados, afirmaram, não existir qualquer tipo de processo de formação, seja ele estruturado ou não internamente para qualificá-los e capacitá-los.

Por conseguinte, foi preciso entender a importância de um processo estruturado de formação profissional interna como ferramenta de maximização de resultados para uma empresa do ramo contábil, o que após a aplicação da pesquisa descobriu-se ser importante devido ao encerramento dos abismos profissionais (pouco conhecimento), por parte dos contabilistas, além de busca por crescimento profissional de forma mais rápida dentro da empresa, e impactação direta no desempenho da equipe tornando-os preparados para desenvolver suas funções com agilidade, eficiência e eficácia.

Diante do que fora descoberto pela pesquisa é importante sugerir a criação de um processo estruturado de formação profissional interna para a qualificação e capacitação dos colaboradores contábeis como ferramenta de maximização de resultados, pois isso irá fazer com que os contabilistas produzam mais e melhor e evitando erros, além de potencializar maiores lucros através da satisfação dos clientes com os serviços recebidos e com a posterior indicação da empresa para outros clientes, além de um aumento no valor de suas remunerações e uma possível ascensão a novos cargos dentro da empresa.

Assim o presente estudo não pretende ser conclusivo, e sugere para trabalhos futuros uma pesquisa sobre a oportunidade de crescimento profissional dentro da empresa, após esse processo de formação, qualificação e capacitação profissional, sendo que tais colaboradores vivem dentro de um cenário globalizado e competitivo. 


\section{Referências}

BEUREN, Ilse Maria. Como elaborar trabalhos monográficos em Contabilidade: teoria e prática. $4^{\mathrm{a}}$ ed. São Paulo: Atlas, 2008.

BORGES, Juarez Camargo. A Qualificação Profissional do Trabalhador para o Mercado de Trabalho e Ambiente Organizacional. Disponível em: https://www2.faccat.br/portal/sites/default/files/borges.pdf. Acesso em: 17/02/2018.

BRASIL. Lei $\mathrm{n}^{\circ} .11 .788$ de 25 de setembro de 2008 que dispõe sobre o estágio de estudantes. Lex: legislação federal, Brasília, set. 2008.

CHIAVENATO, Idalberto. Gestão de Pessoas: o novo papel dos recursos humanos nas organizações. $4^{a}$ ed. São Paulo: Manole, 2014.

Conceito de formação - O que é, definição e significado. Disponível em: https://conceito.de/formacao. Acesso em: 12/02/2018.

Conheça os desafios do mercado de contabilidade e saiba como se dar bem na área. Disponível em: https://www.unicesumar.edu.br/blog/desafios-do-mercado-de-contabilidade/. Acesso em: 16/10/2017.

Cursos profissionalizantes (Capacitação - Qualificação - Formação Continuada.

Disponível em: www.cefope.rn.gov.br/Conteudo.asp?TRAN=ITEM\&TARG=8645... Acesso em: 14/02/2018.

DASSOLERI, Olmira Bernadete; LIMA, Denise Maria Soares. A formação e a profissionalização docente: características, ousadia e saberes. Disponível em: www.ucs.br/etc/conferencias/index.php/anpedsul/9anpedsul/paper/view/3171/522. Acesso em: $12 / 02 / 2018$.

DIAS, Lidiane Nazaré da Silva; MOREIRA, Anna Carolina Silva. As perspectivas da profissão contábil para os formandos em Ciências Contábeis do Instituto de Estudos Superiores da Amazônia - IESAM. Disponível em: www.congressocfc.org.br/hotsite/trabalhos_1/482.pdf. Acesso em: 17/02/2018.

Entenda a Diferença entre Capacitação e Qualificação profissional. Disponível em: http://www.jrmcoaching.com.br/blog/entenda-a-diferenca-entre-capacitacao-e-qualificacaoprofissionall. Acesso em: 15/02/2018.

FAVERO, Hamilton Luiz, LONARDONI, Mário, Souza, Clóvis de, TAKAKURA, Massakazu. Contabilidade Teoria e Prática. $6^{\text {a }}$ ed. São Paulo: Atlas, 2011.

FONSECA, Celso Suckow. História do Ensino Industrial no Brasil. Rio de Janeiro Escola Técnica, 1961. v.1.

Formação Profissional: O Conceito.

Disponível em: https://www.forma-te.com/formacao-profissional-o-conceito. Acesso em: 13/02/2018.

FROZINO, Alessandra Damas. FORMAÇÃO PROFISSIONAL: percursos e desafios para a escolha de carreira. 
Disponível em: www.ppga.com.br/mestrado/2006/frozino-alessandra damas.pdf. Acesso em: 13/02/2018.

GARCIA, Sandra Regina de Oliveira. O fio da história: a gênese da formação profissional no BRASIL.

GIL, Antônio Carlos. Como elaborar projetos de pesquisa. 6ª ed. São Paulo: Atlas, 2017.

GIL, Antônio Carlos. Métodos e Técnicas de Pesquisa Social. 6ª ed. São Paulo: Atlas, 2008.

GRAMIGNA, Maria Rita. Modelo de competências e gestão dos talentos. $2^{\mathrm{a}}$ ed. São Paulo: Pearson Prentice Hall, 2012.

IUDICIBUS, Sérgio de, MARION, Jose Carlos. Curso de Contabilidade Para não Contadores. $7^{\mathrm{a}}$ ed. São Paulo: Atlas, 2011.

LACOMBE, Francisco José M. Recursos Humanos: Princípios e Tendências. $2^{a}$ ed. São Paulo: Saraiva, 2011.

LEI, No 9.394, de 20 de Dezembro de 1996. Lei de Diretrizes e Bases da Educação Nacional - LDB, artigo 21 .

LIBANIO, João Batista. A arte de formar-se. $4^{a}$ ed. São Paulo: Edições Loyola, 2010.

MINAYO, M. C. Ciência, técnica e arte: o desafio da Pesquisa Social. In: (Org.) Pesquisa social: teoria, método e criatividade. $28^{\text {a }}$ ed. Petrópolis: Vozes, 2009, p. 09-30.

NEVES, Lúcia M. W. A Hora e a Vez da Escola Pública: um estudo sobre os determinantes da política educacional do Brasil de hoje. Rio de Janeiro: UFRJ, 1991. Tese de doutorado.

NOSSA, Silvania Neris; FONSECA, Carlos Roberto Gama da; TEIXEIRA, Aridelmo José Campanharo. Formação do Profissional de Ciências Contábeis: Multidisciplinar ou Interdisciplinar? Disponível em: www.fucape.br/_public/producao.../Nossa,\%20Formação\%20do\%20Profissional.pdf. Acesso em: $12 / 02 / 2018$.

O que é formação profissional.

Disponível em: http://www.portaleducacao.com.br/pedagogia/artigos/24956/o-que-e-formacaoprofiss... Acesso em: 16/02/2018.

OLIVEIRA, Leandro José de; RAUSCHKOLB, Alan Santana Rauschkolb; LOPES, Cristiana Pereira Serra; VIEIRA, Mariana Torres Licursi; MACIEL, Wilton Rogério Santos. Capacitação de funcionários como diferencial em um mundo globalizado: o caso da ascomim em mato grosso. Disponível em: www.convibra.com.br/dwp.asp?id=4963\&ev=25. Acesso em: 14/02/2018.

PORTAL DA EDUCAÇÃO. Disponível em: https://www2.portaleducacao.com.br > Home > Artigos > Educação e Pedagogia. Acesso em: 17/02/2018.

Qualificação x Capacitação.

Disponível em: https://blogsicurezzaeditora.wordpress.com/tag/qualificacao-x-capacitacao/. Acesso em: 10/02/2018. 
RODRIGUES, Ana Kátia da Silva. O profissional contábil e as exigências do mercado de trabalho no município de Juína.

Disponível em: www.biblioteca.ajes.edu.br/arquivos/monografia_20110809162110.pdf. Acesso em: 13/02/2018.

ROMANELLI, Otaíza de O. História da Educação no Brasil (1930/1973). Petrópolis: Vozes, 1980.

SÁ, Antônio Lopes. Ética Profissional. $9^{a}$ ed. Atlas S/A São Paulo-2009.

SANTOS, Adailton de Jesus. Estágio e desenvolvimento de competências: estudo de caso sobre o programa de estágio na gerência executiva do instituto nacional do seguro social em santo Antônio de jesus - Bahia. Bahia: UNEB, 2014. Monografia 2014.

SCREMIN, Mariles Vieira Mangili. Investir em capacitação é um bom negócio para as organizações? Disponível em: https://www.portaleducacao.com.br > Home > Artigos > Recursos Humanos. Acesso em: 17/10/2017.

SEVERINO, Antônio Joaquim. Metodologia do trabalho cientifico. $24^{a}$ ed. Rev. e atual. São Paulo: Cortez, 2016.

SILVA, Antônio Carlos Ribeiro da. Metodologia da pesquisa aplicada à contabilidade: Orientações de estudos, projetos, relatórios, monografias, dissertações, teses. $3^{\text {a }}$ ed. São Paulo: Atlas, 2010.

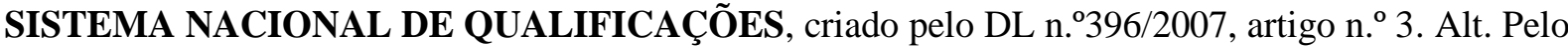
Decreto Lei n. ${ }^{\circ}$ 14/2017. Disponível em: https://www.ina.pt/index.php/coordenacao-formacaoap/legislacao-aplicavel. Acesso em: 17/02/2018.

Thomas, J.R.; Nelson, J.K. Métodos de pesquisa em educação física, $3^{\text {a }}$ ed. São Paulo: Artmed, 2002.

Tipos de Formação.

Disponível em: https://www.vestibulandoweb.com.br/formacao.htm. Acesso em: 17/02/2018

VIDIGAL, Cláudia B. R.; VIDIGAL, Vinícius G.; Investimento na qualificação profissional: uma abordagem econômica sobre sua importância. 2012.

Como citar este artigo (Formato ABNT):

FONSECA, Ubaldo de Jesus; OLIVEIRA, Vinicius Motta. Estruturação do Processo de Formação Interna: Um Estudo de Caso em uma Empresa do Ramo Contábil. Id on Line Revista Multidisciplinar e de Psicologia, 2018, vol.12, n.41, p.102-123. ISSN: 1981-1179.

Recebido: 31.05 .2018

Aceito: 11.06 .2018 